\title{
A Study on the Dynamic Efficiency of Logistics-IT Companies
}

\author{
HyunWoo Goh \\ Dept. of Industrial Management System Engineering, Seokyeong University \\ 16-1 Jungneung-Dong, Sungbuk-Ku, Seoul 136-704, Korea \\ skuie@naver.com
}

\begin{abstract}
In this study, we assessed the dynamic efficiency to evaluate the efforts to improve the efficiency of logistics-IT companies. The efficiency trend and stability of logistics-IT companies were analyzed through analysis of dynamic efficiency changes, and the efficiency was analyzed by analyzing the changes in efficiency, and suggesting ways to improve efficiency.
\end{abstract}

Keywords: comparative efficiency, Data Envelopment Analysis (DEA), decision making unit (DMU), Malmquist Productivity Index (MPI)

\section{Introduction}

In recent years, 'logistics' has evolved from the simple movement of 'things', and is being developed smartly through the combination of IT technology and creative services. In particular, the logistics-IT industry is expected to accelerate further as the fourth industrial revolution has arrived.

US retailers are waging a war on shipping, and the competition is getting more intense as they are also in the logistics-IT market.

Amazon used the Web Store service to link online shopping malls, payment systems, and logistics infrastructures with external systems, making it the basis for development. In particular, the unmanned aerial drones, called PrimeAir, are equipped with built-in GPS and advanced imaging technology, along with stability and accuracy. In addition, the accuracy of the logistics work efficiency is improved by placing the robot in the workplace. The accuracy of the logistics robot is proved to be $99.99 \%$.

Since the event of 11 September, Google has also been actively pursuing logistics-IT with an interest in 'logistics security'. Based on a solid Android platform, it is leading the logistics-IT system by applying and extending Google Earth and unmanned vehicles to the logistics system.

In the case of Amazon and Google, the logistics industry is newly developing along with the development of IT technology, which is called "new fusion logistics". This is a fusion of 'traditional logistics industry', which pursues logistics cost reduction and efficiency, and 'knowledge industry' such as IT, BT and CT. This can be seen as a creative logistics technology and service for creating high added value.

The types of new fusion logistics are very diverse, and logistics-IT is being done by technological development and convergence in various directions. In particular, it is noteworthy that the logistics market has diversified and expanded in various fields and aimed at the integration of systems. Until now, logistics policies differ from those in which logistics costs have been reduced rather than market expansion.

According to KOTI(the Korea Transport Institute) (2015), based on the actual state of the national logistics plan $(2011 \sim 2020)$ and analysis of its performance, and the situation and prospects of domestic and overseas logistics conditions, It suggests 'ICT-based Smart

Received (November 26, 2017), Review Result (January 26, 2018), Accepted (February 19, 2018) 
Logistics Informatization Promotion' as the basic task of developing smart logistics technology for the future and fostering IT business.

This trend is expected to accelerate the application of IT to the logistics industry, and logistics-IT companies will be able to expand the market.

Finally, in order to increase the efficiency of the logistics industry, it is important to build a logistics system. However, most logistics companies have limited access to logistics systems, and most will benefit from IT companies. In particular, these companies are called logistics-IT companies, which provide IT-related solutions, systems, equipment, training, consulting, etc., to the logistics and logistics functions of logistics specialists, shippers and general companies.

As the logistics industry changes, logistics-IT companies are also active, but these companies tend to be influenced by the performance of the logistics industry as a whole. As a result, the efficiency of each internal company has become an important issue to cope with the external environment.

The purpose of this study is to improve the competitiveness of logistics-IT companies by analyzing dynamic productivity trends in order to cope with changing business environments and analyzing the trends of efficiency in corporate management. To do this, we use the Malmquist Productivity Index (MPI) analysis.

\section{Malmquist Productivity Index}

Although the DEA analysis can measure the efficiency of each year at a certain point in time, there is some limit to understanding the change in the productivity of each decision unit as a function of time during the analysis period.

In this study, MPI is used to measure productivity changes.

The calculation formula of MPI is as follows equation (Färe et al., 1994).

$$
\begin{aligned}
& M\left(x^{t+1}, y^{t+1}, x^{t}, y^{t}\right) \\
& =\left[\frac{D_{0}^{t}\left(x^{t+1}, y^{t+1}\right)}{D_{0}^{t}\left(x^{t}, y^{t}\right)} \times \frac{D_{0}^{t+1}\left(x^{t+1}, y^{t+1}\right)}{D_{0}^{t+1}\left(x^{t}, y^{t}\right)}\right]^{\frac{1}{2}} \\
& =\frac{D_{0}^{t}\left(x^{t+1}, y^{t+1}\right)}{D_{0}^{t}\left(x^{t}, y^{t}\right)} \times\left[\frac{D_{0}^{t}\left(x^{t+1}, y^{t+1}\right)}{D_{0}^{t+1}\left(x^{t+1}, y^{t+1}\right)} \times \frac{D_{0}^{t}\left(x^{t}, y^{t}\right)}{D_{0}^{t+1}\left(x^{t}, y^{t}\right)}\right]^{\frac{1}{2}} \\
& =\text { Technical Efficiency Change Idex(TECI) } \times \\
& \text { Technical Change Idex }(\text { TCI })
\end{aligned}
$$

Generally, $M\left(x^{t+1}, y^{t+1}, x^{t}, y^{t}\right)>1$ means productivity increases over two periods, and $M\left(x^{t+1}, y^{t+1}, x^{t}, y^{t}\right)<1$ means productivity decreases at $t+1$ compared to $t$. The MPI of Eq. (1) can be decomposed as shown in Eq. (2). On the left of Eq. (2), arbitrary DMUs between ' $t$ ' and ' $t+1$ ' technical efficiency change index (TECI), which measures how close to the "production frontier" is, and the right-hand bracket expression measures the technical change index (TCI) that assesses how production technology changes between the two periods contribute to productivity changes MPI $=$ TECI $x$ TCI.

In general, TECI is a measure for evaluating the efficiency variation at the technical level of the constant return scale (CRS) of two periods. If TECI $>1$, it means that it is closer to the production change line at $t+1$ than at $\mathrm{t}$. (TECI $<1$ ), which means that there is a catching-up effect similar to that of the producers who demonstrate the maximum efficiency of the technology. In this way, TECI is an index that measures how far away from the production change line, due to learning and knowledge spreading effect, market competitiveness, cost structure and improvement of facility utilization rate through pursuit 
effect through internal operational efficiency.

On the other hand, TCI is an index that measures how productivity and change caused by changes in technology and the external environment, that is, by efficient change lines, between the two periods up to $t+1$ compared to the time $t$. As TCI increases production lines more and more, it increases the possibility of more output with the same amount of input, which means technological progress (TCI > 1). However, in the opposite case, it means that the technical degeneration (TCI < 1) occurred. This reflects innovation potential and is influenced by factors that shift the production possibility curve, such as new product and process innovation, new management techniques, external impact

The TECI of Equation (2) can be decomposed into the pure efficiency change index (PECI) and the scale efficiency change index (SECI) as shown in Equation (3).

$$
\begin{aligned}
& \text { TECI }=\frac{D_{0}^{t+1}\left(x^{t+1}, y^{t+1}\right)}{D_{0}^{t}\left(x^{t}, y^{t}\right)} \\
& =\frac{D_{\text {vrs }}^{t+1}\left(x^{t+1}, y^{t+1}\right)}{D_{\text {vrs }}^{t}\left(x^{t}, y^{t}\right)} \times\left[\frac{D_{c r s}^{t+1}\left(x^{t+1}, y^{t+1}\right) \times D_{\text {vrs }}^{t}\left(x^{t}, y^{t}\right)}{D_{\text {crs }}^{t}\left(x^{t}, y^{t}\right) \times D_{\text {vrs }}^{t+1}\left(x^{t+1}, y^{t+1}\right)}\right] \\
& =P E C I \times S E C I
\end{aligned}
$$

While PECI measures how close the DMU approaches the efficient frontier at the level of the variable return scale (VRS), the SECI measures how much the DMU has achieved economies of scale.

\section{Research Framework}

The framework of this study is shown in Figure 1, and the preparation phase for dynamic efficiency analysis and the analysis of five change indexes are conducted.

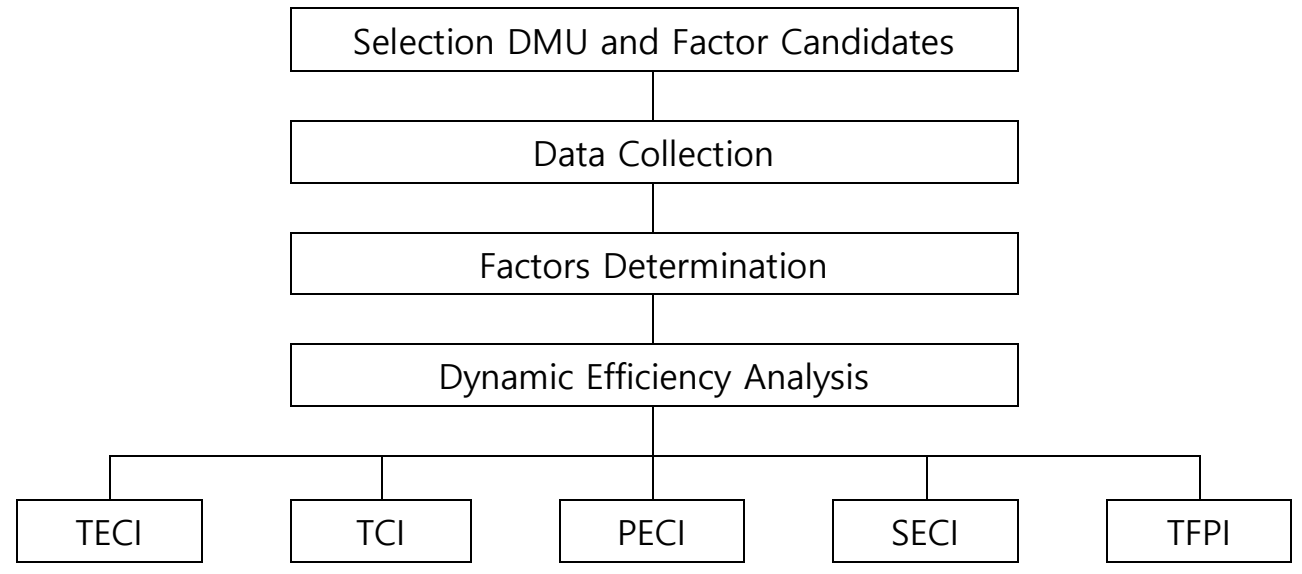

Figure 1. Research Framework

\section{Empirical Analysis}

We conduct a dynamic efficiency analysis according to the research process in Figure 1.

\subsection{Selection DMU and Factor Candidates}

DMU selects five logistics-IT companies listed on the stock exchange. We select the asset as a candidate for the input factor and the sales and operating profit as the candidate for the output factor. 


\subsection{Data Collection}

Data for input and output element candidates for five DMUs are collected for five years from 2012 to 2016.

\subsection{Factors Determination}

As a result of analyzing the correlation between factor candidates, the correlation between the input factor and the output factor is significant at the level of 0.01 (both sides), and all of the candidates are determined as the final input factor and the output factor.

\subsection{Dynamic Efficiency Analysis}

The MPI (Malmquist Productivity Index) is used for dynamic efficiency analysis, which is a method for estimating the growth rate of TFP (Total Factor Productivity). MPI can be obtained from the product of TECI and TC.

TECI is a measure of technological efficiency changes at two points, and TCI is a measure of how production technology changes between the two periods, i.e., the shift to efficient boundaries, contribute to productivity changes. TECI can be divided into PECI and SECI.

4.4.1. TECI Analysis: As a result of the TECI analysis from 2012 to 2016, it can be seen that the average technical efficiency of five DMUs increased except 2012-2013 (0.722) (<Figure 2>). In particular, technological efficiency has increased significantly from 2013 to 2014 (20.805). As shown in Figure 3, the TECI is 5.901, which means that the technological efficiency has increased.

In the case of individual DMUs, three DMUs (D02, D03, D04) with increased technical efficiency on average and the other two DMUs (D01, D02) proved to have decreased technological efficiency. D03 (25.544) was the highest among the DMUs with increased technological efficiency. In particular, the increase in 2014 was the largest in 2013. This is reflected in the fact that operating loss will occur in 2012, sales will be negative in 2013, and operating loss will increase. On the other hand, DMU with the lowest technical efficiency is D01 (0.798).

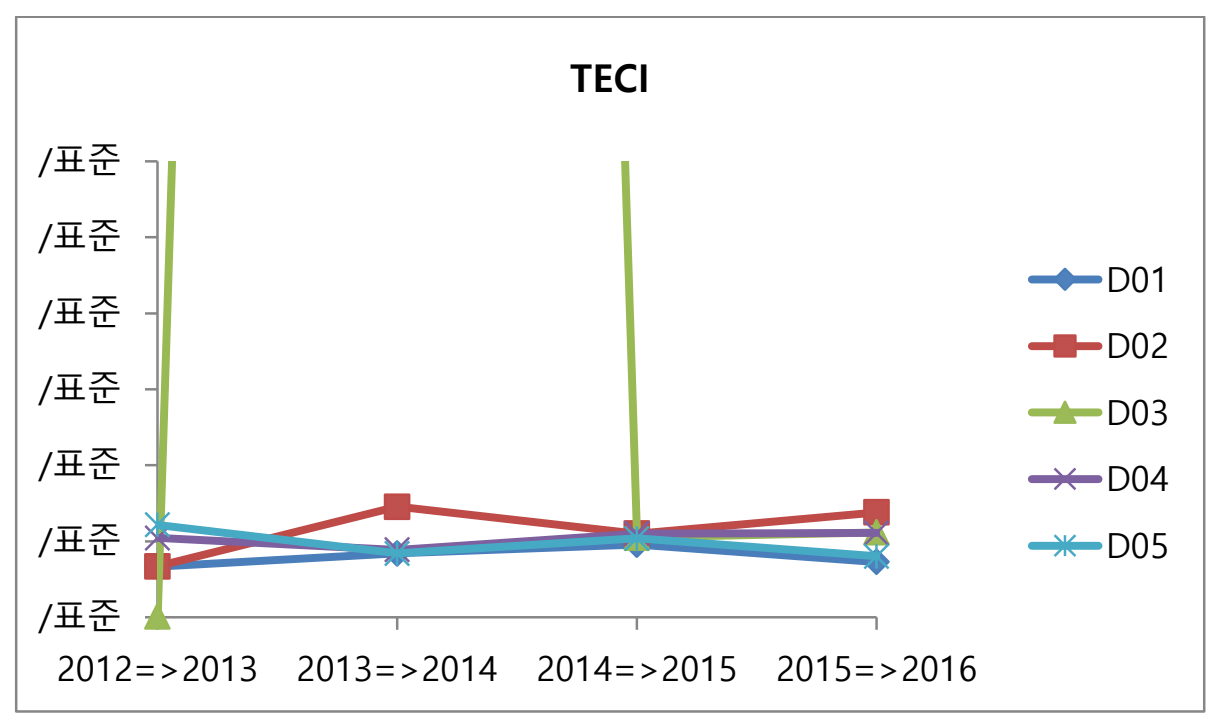

Figure 2. TECI 


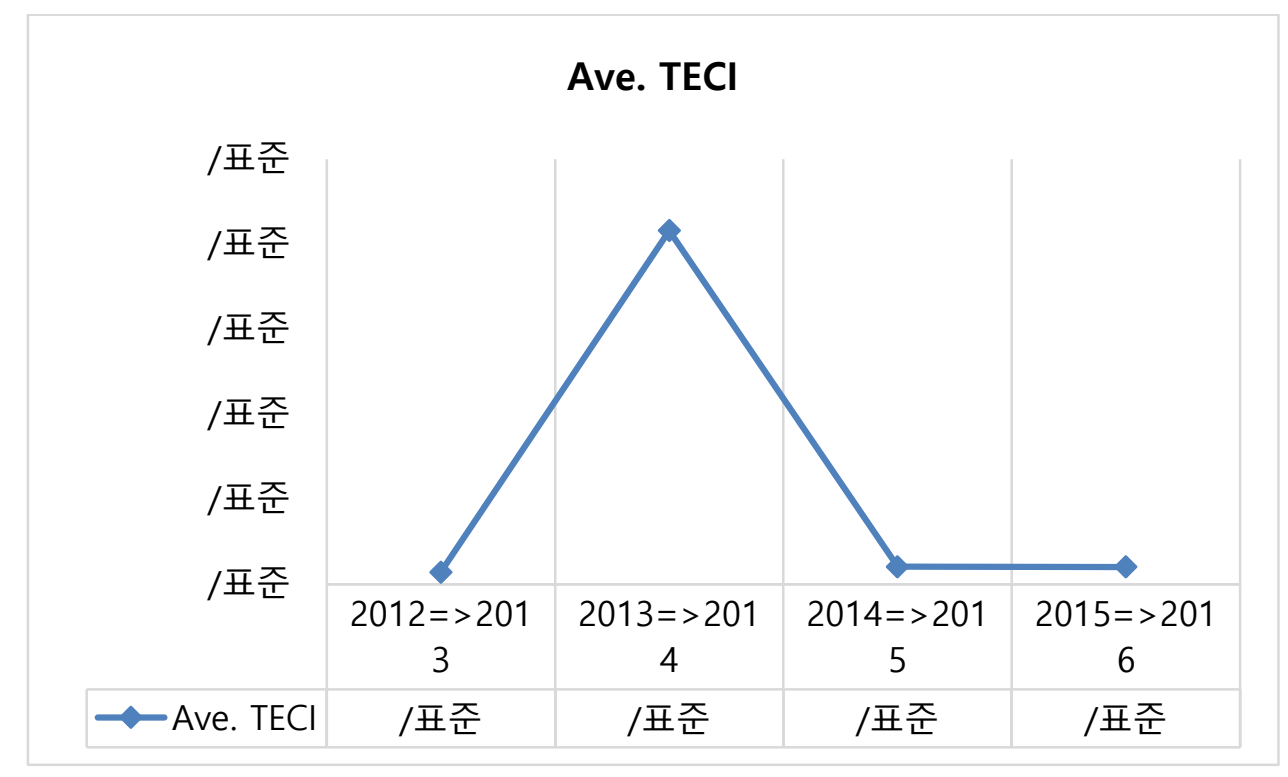

Figure 3. Average TECI

4.4.2. TCI Analysis: As a result of the TECI analysis from 2012 to 2016, the five-year average change in technology for five DMUs has progressed from 2012 to 2013 (1.017) and 2013 to 2014 (1.025), but from 2014 to 2015 (0.893) and 2015 (Figure 4), and the technology change index is 0.979 for the 5-year average (Figure 5).

In the case of individual DMUs, on average only D01 (1.060) has advanced and the remaining four DMUs can see that the technology is degraded.

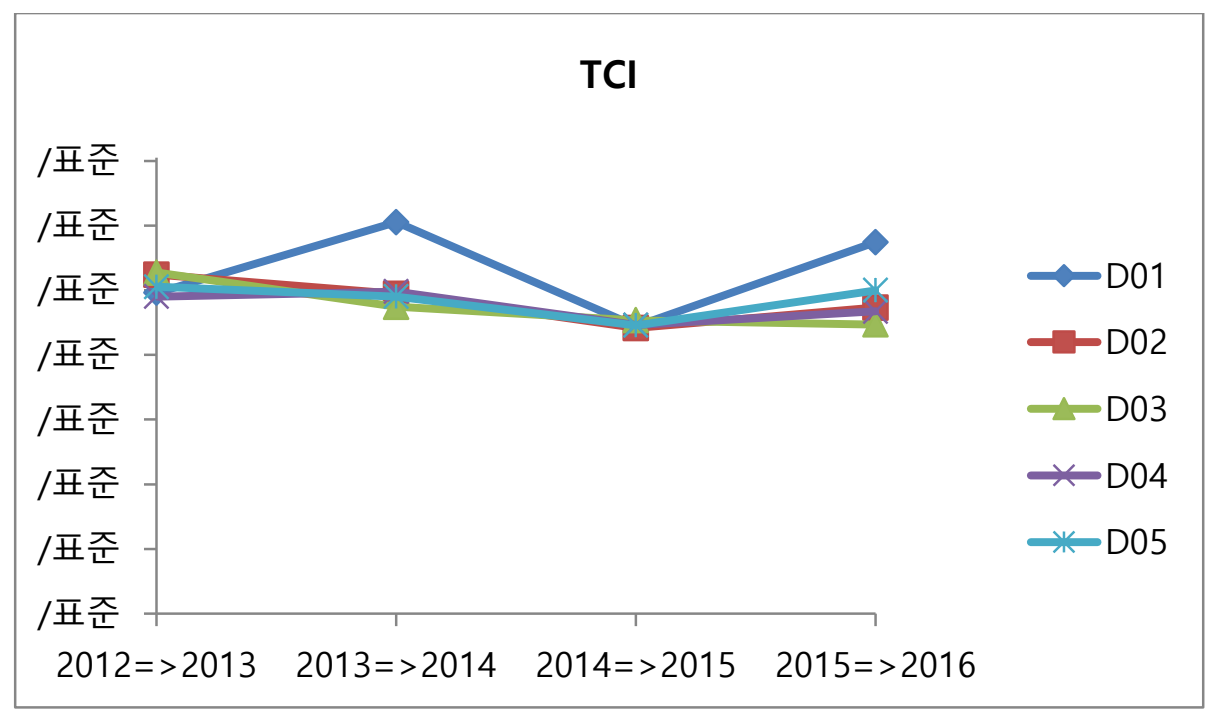

Figure 4. TCl 


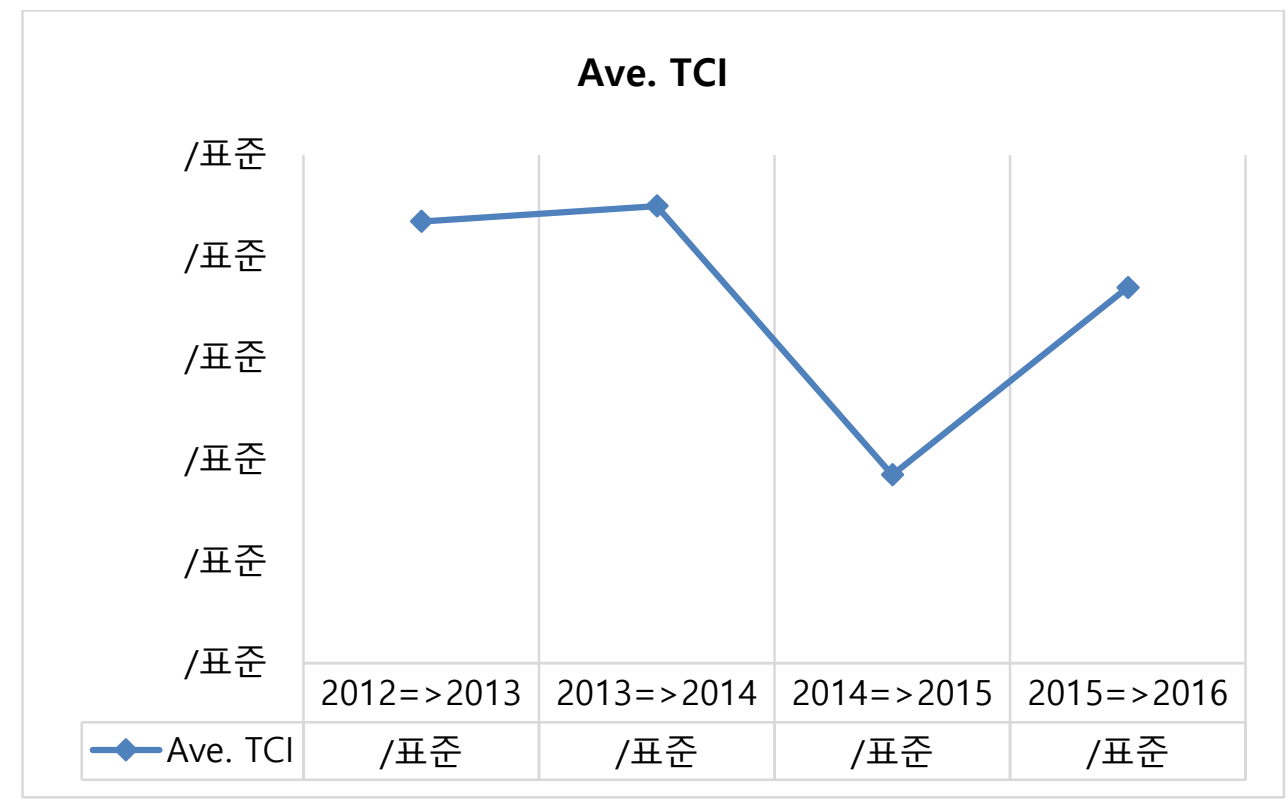

Figure 5. Average TCI

4.4.3. PECI Analysis: As a result of the PECI analysis from 2012 to 2016, the average five-year PECI for five DMUs declined after increasing from 2012 to 2013 (1.133) (Figure 6), with an average increase of PECI to 1.013 (Figure 7). The average DMU D04 (0.973) in the case of the individual DMU decreased PECI, indicating that it affected the overall average. D03 (1.093) shows an increase in PECI, and D01, D02, and D05 show that PECI is stagnated at 1.000 .

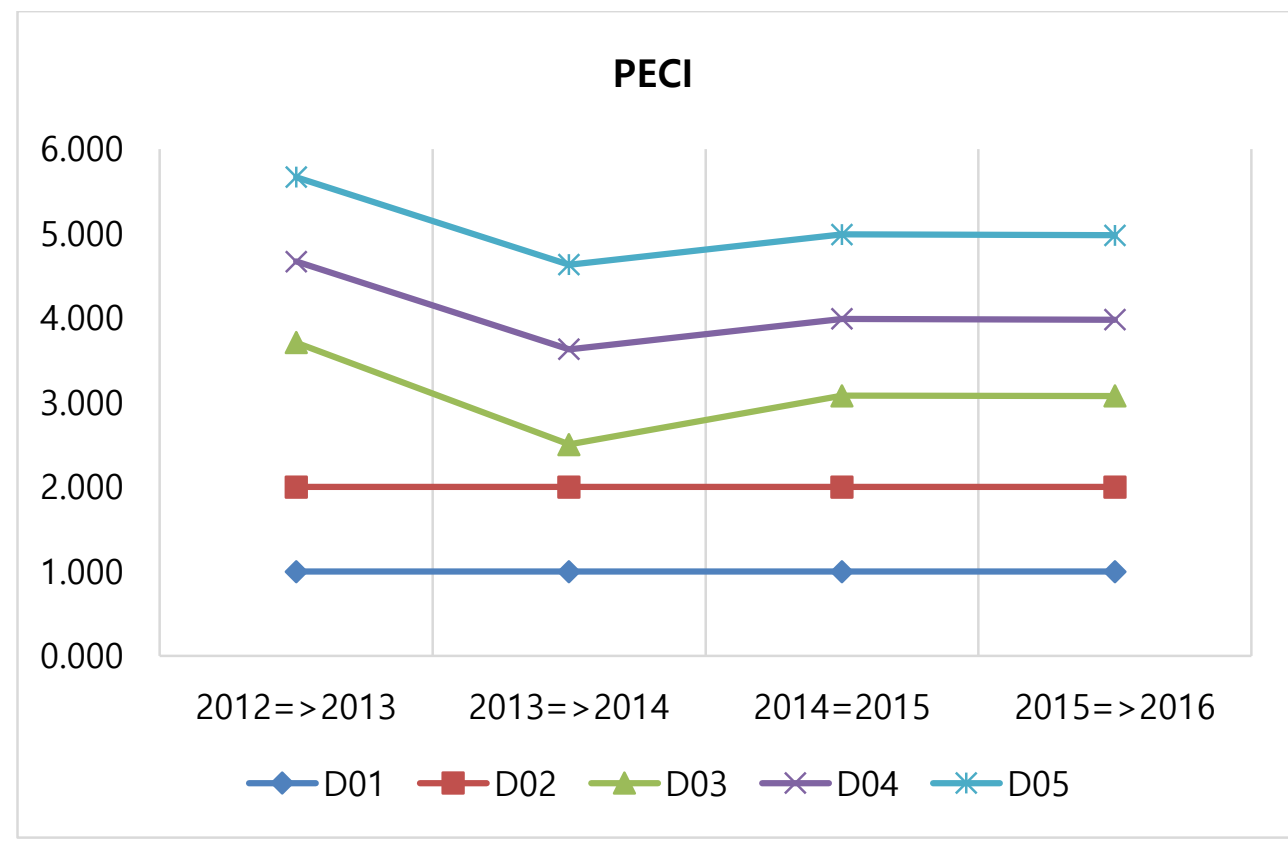

Figure 6. PECI 


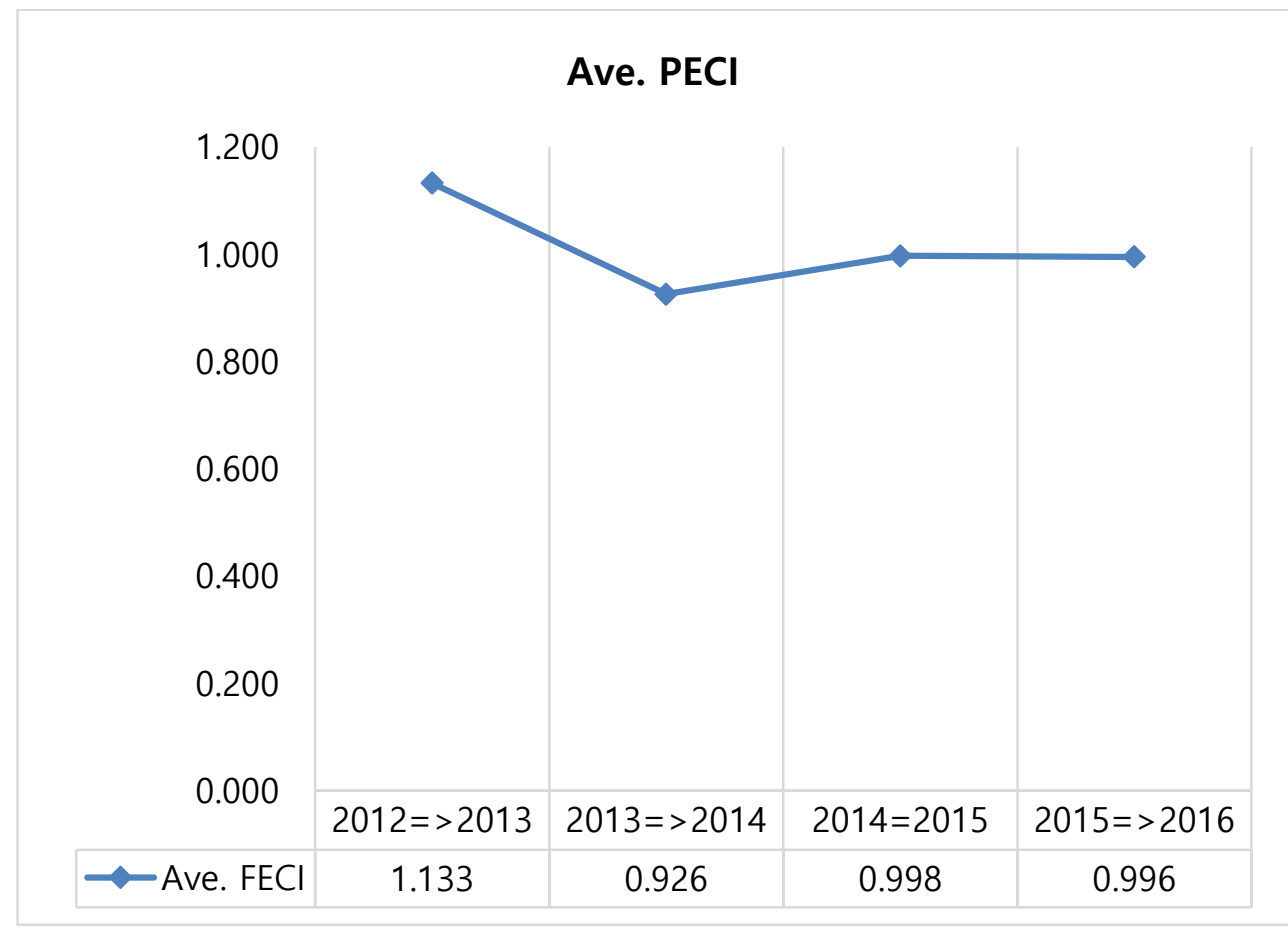

Figure 7. Average PECI

4.4.4. SECI Analysis: As a result of the SECI analysis from 2012 to 2016, the average five-year average SECI for five DMUs declined from 0.735 in 2012 to 2013, but thereafter increased in SECI (Figure 8). On the average, the SECI has increased significantly to 23.911 (Figure 9).

In the case of individual DMUs, DMU D02 (1.153) and D03 (115.404) were increased only, while the remaining DMUs were stagnant at 1.000. DMU D03's overall improvement in operating performance was found to have had an overall impact.

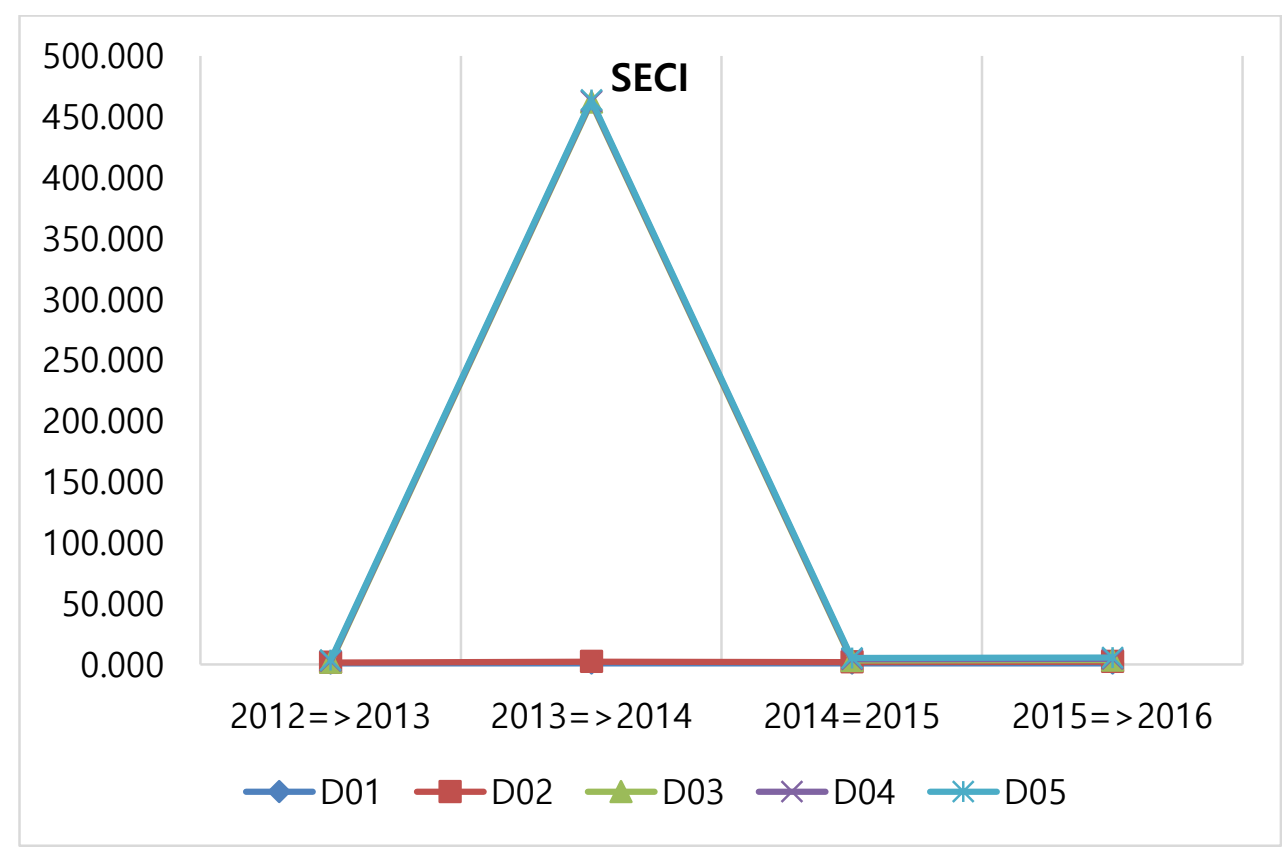

Figure 8. SECI 


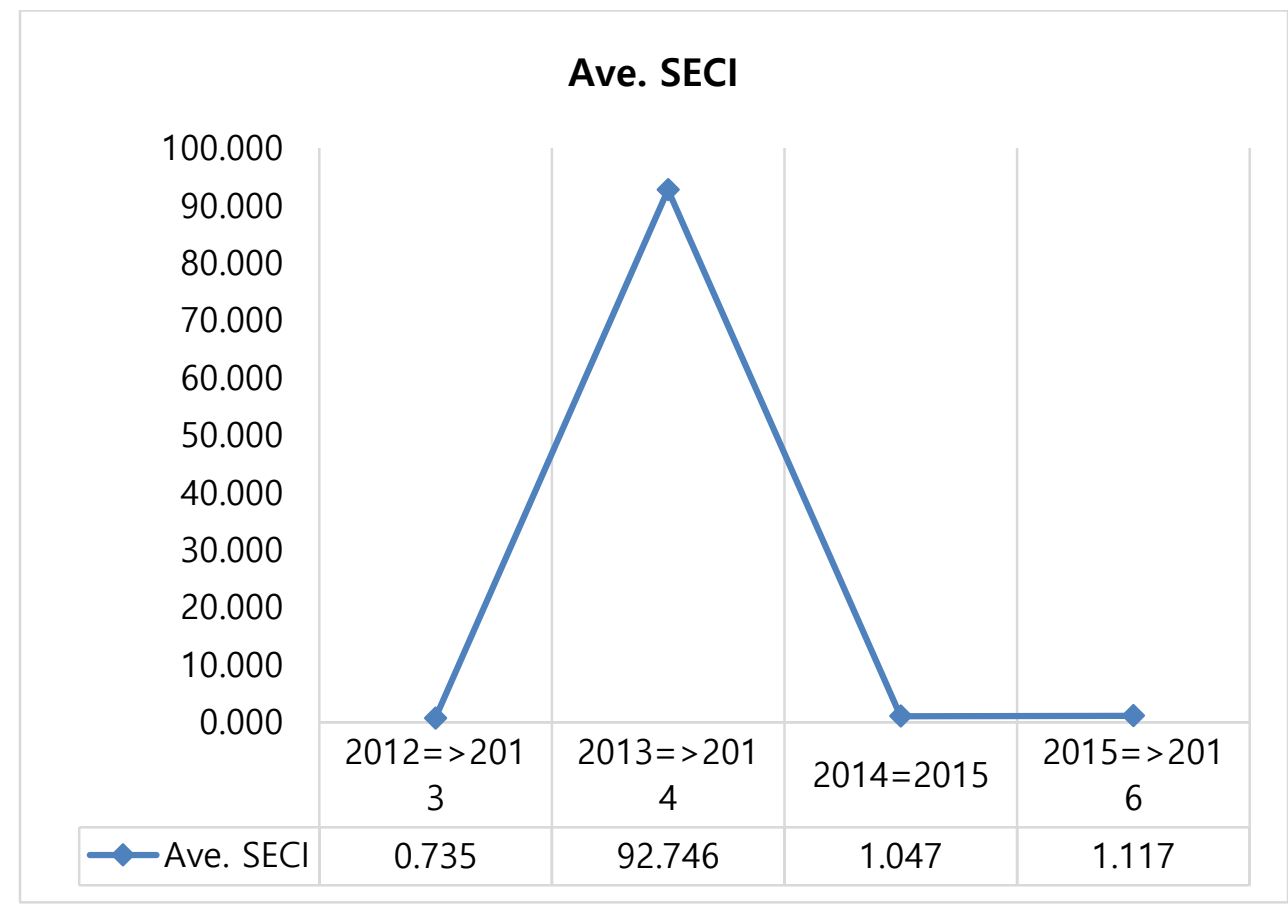

Figure 9. SECl

4.4.5. TFPI Analysis: TFPI means a comprehensive change of each index (Figure 10). Looking at the TFPI from 2012 to 2016, the productivity of five DMUs declined except for the average TFPI 2014 - 2015 (19.818) for five years, but the average TFPI improved to 5.618. This suggests that DMU D03 's substantial improvement in operating performance has been influential.

In the case of individual DMUs, on average DMU D02 (1.106) and D03 (24.216) are excluded, and the remaining three DMUs show that TFPI has fallen.

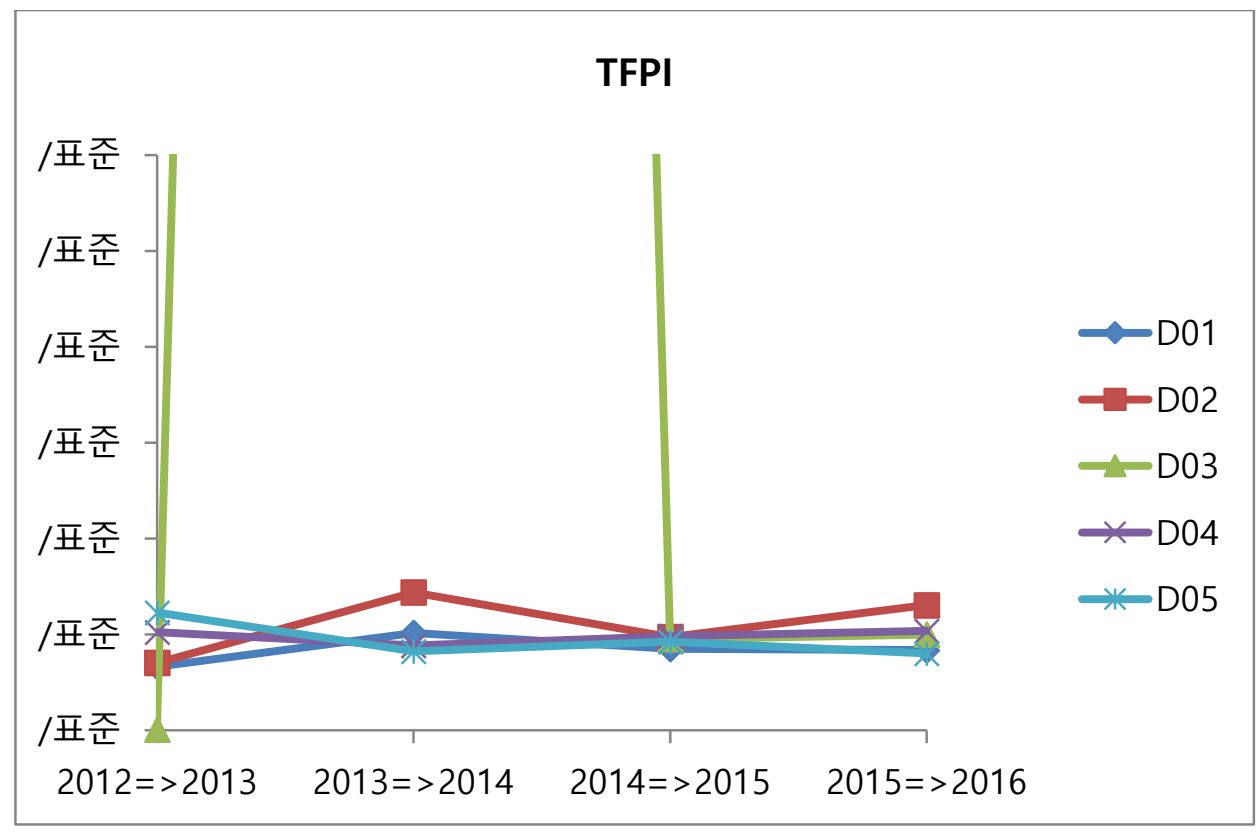

Figure 10. TFPI 


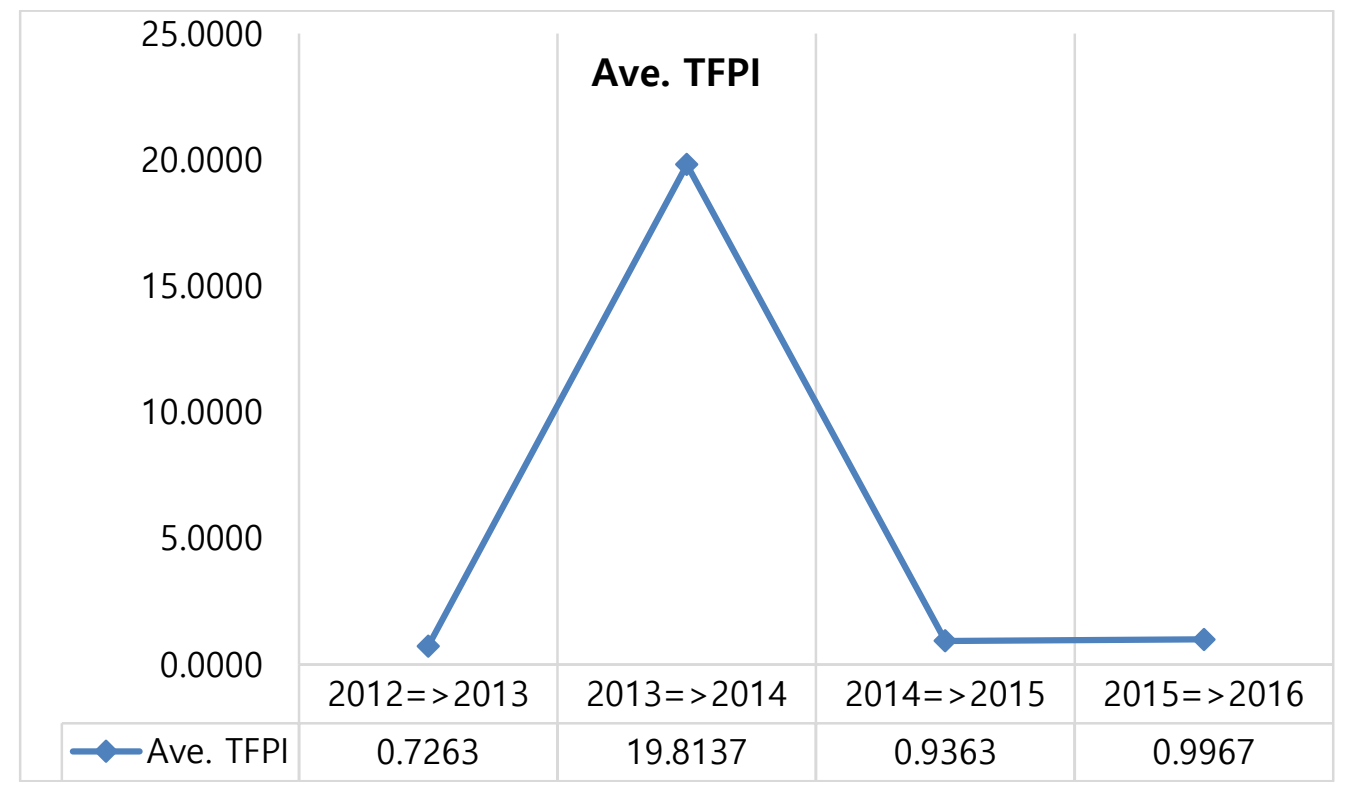

Figure 11. TFPI

\section{Conclusion}

In this study, the efficiency change of logistics-IT companies according to time change was analyzed. MPI was used for this purpose. A summary of analyzed MPIs is provided in Table 1 and Figure 12 respectively.

On average, TFPI (5.618) increased from 2012 to 2016. However, only TCI (0.980) decreased, indicating that the technology has deteriorated. In particular, TECI (5.901) and SECI (2.631) showed a large increase, leading to an increase in TEPI.

For the five-year period up to 2016 at one-year intervals starting in 2012, the index fell for TFPI excluding $2013 \Rightarrow 2014$ (19.814). Excluding PECI (0.926) in 2013, the remaining indexes rose in 2014, with TECI (20.805) and SECI (7.585) leading the rise in TEPI. On the other hand, TECI can be classified into PECI (0.926) and SECI (7.585). The increase in scale efficiency can be attributed to the increase in TECI.

TECI decreased only during $2012 \Rightarrow 2013$ and increased during the rest of the year. TCI

$2012=>2013$ (1.017), $2013 \Rightarrow 2014$ (1.025), but it decreased in the remaining period and decreased on the average.

The PECI is decreasing after 2012 => 2013 (1.133), so the cause analysis and countermeasures are needed.

The SECI is not stable due to the upward and downward trends repeated after the decrease in $2012=>2013(0.958)$, and the cause analysis and countermeasures are required.

Table 1. Summary of TPIs

\begin{tabular}{|c|r|r|r|r|r|}
\hline Index Period & $2012=>2013$ & $2013=>2014$ & $2014=>2015$ & $2015=>2016$ & \multicolumn{1}{c|}{ Average } \\
\hline TECI & 0.722 & 20.805 & 1.049 & 1.028 & 5.901 \\
\hline TCI & 1.017 & 1.025 & 0.893 & 0.985 & 0.980 \\
\hline PECI & 1.133 & 0.926 & 0.998 & 0.996 & 1.013 \\
\hline SECI & 0.958 & 7.585 & 0.980 & 1.003 & 2.631 \\
\hline TFPI & 0.726 & 19.814 & 0.936 & 0.997 & 5.618 \\
\hline
\end{tabular}




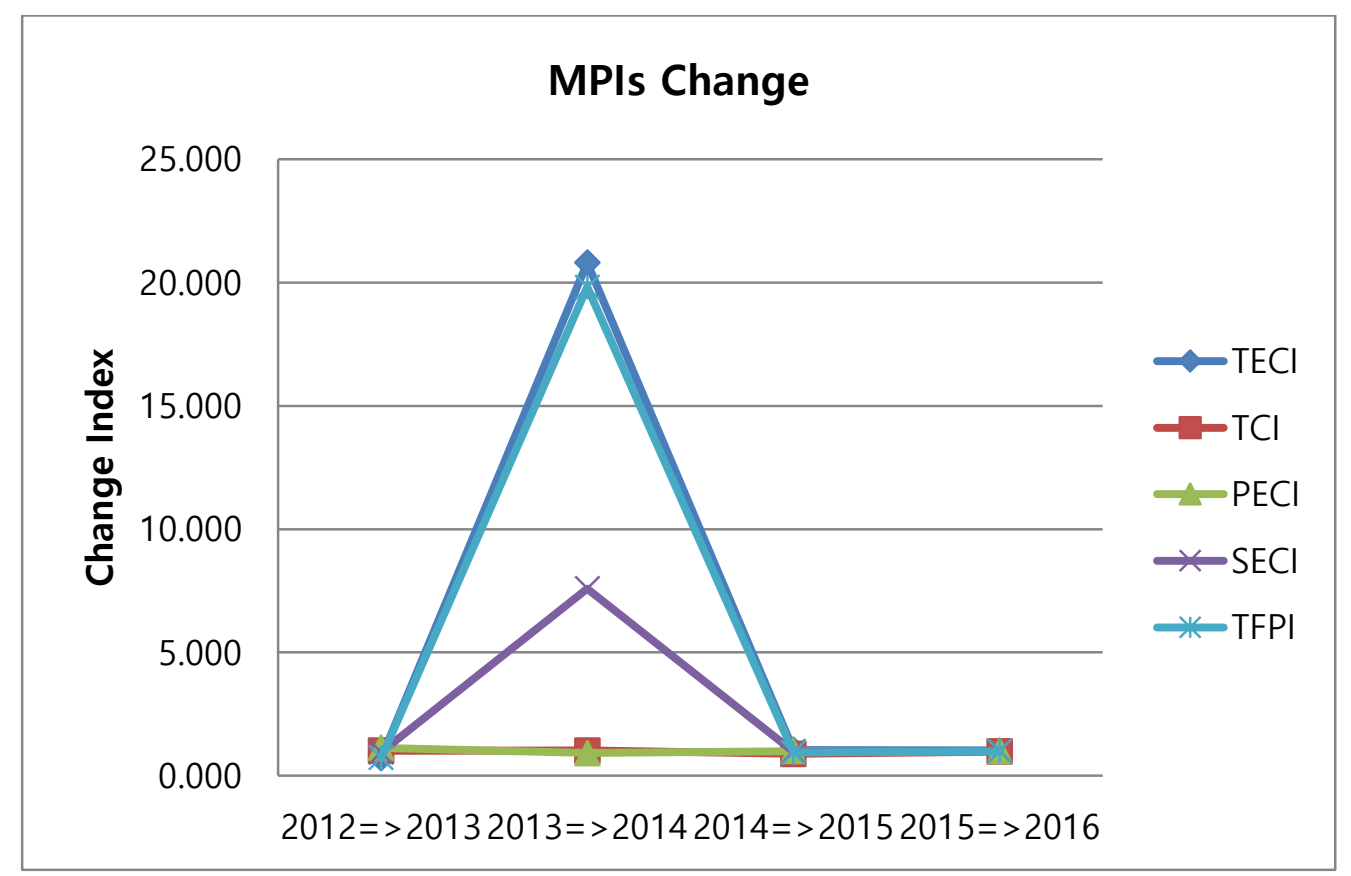

Figure 12. MPIs Change

\section{Acknowledgement}

This paper is a revised and expanded version of a paper entitled "Analysis of the Static and Dynamic Efficiency of Logistics-IT Companies" presented at "2017 $1^{\text {st }}$ International Workshop on Cultural and Technological Exchange and Mutual Development of the Pacific Rim Countries (CuTEMD 2017), Namseoul University, Cheonan, Korea, December 17, 2017”.

Also, this research was supported by Seokyeong University in 2017.

\section{References}

[1] G. Appa, "A New Framework for the Solution of DEA Models", European Journal of Operational Research, vol. 172, (2006), pp. 604-615.

[2] R. D. Banker and W. W. Cooper, "Some Models for Estimating Technical and Scale Inefficiencies in Data Envelopment Analysis", Management Science, vol. 39, no. 9, (1984), pp. 1078-1092.

[3] A. Boussofiand, R. D. Dyson and E. Thanassoulis, "Applied Data Envelopment Analysis", European Journal of Operational Research, vol. 52, no. 1, (1991), pp. 1-15.

[4] A. Charnes, W. W. Cooper and E. Rhodes, "Measuring the Efficiency of Decision Making Units", European Journal of Operation Research, vol. 2, no. 6, (1978), pp. 429-444.

[5] W. D. Cook, K. Tone and J. Zhu, "Data Envelopment Analysis: Prior to Choosing a Model", Omega, vol. 44, (2014), pp. 1-4.

[6] W. W. Cooper, L. M. Seiford and K. Tone, "Data Envelopment Analysis: A Comprehensive Text with Models, Applications, References and DEA-Solver Software", Second Edition, Springer, New York, (2006).

[7] R. Färe and S. Grosskopf, "Malmquist Productivity Indexes and Fisher Ideal Indexes", The Economic Journal, vol. 102, (1992), pp. 158-160.

[8] R. Färe, S. Grosskopf, M. Norris and Z. Zhang, "Productivity Growth, Technical Progress and Efficiency Change in Industrialized Countries", The American Economic Review, vol. 84, no. 1, (1994), pp. 66-83.

[9] H. W. Goh, "Evaluating Efficiency of Financial Performance for KOSDAQ Corporations", Proceedings International Workshop Business 2015, SERSC, (2015), pp. 68-72.

[10] H. W. Goh, "A Study on Evaluating Management Productivity for Logistics-IT Corporations", Advanced Science and Technology Letters, (Information Technology and Computer Science 2016), SERSC, vol. 133, (2016), pp. 201-206.

[11] J. S. Hong, C. J. Yang and H. Y. Lee, "Comparative Evaluation of Efficiency of the Korean IT sectors: A Data Envelopment Analysis Approach”, Journal of the Korea Management Engineers Society, vol. 17, no. 1, (2012) March, pp. 147-160. 
[12] J. H. Kim, "Measuring and Evaluation of Productivity for Logistics-IT Corporations", Asia-pacific Proceedings of Applied Science and Engineering for Better Human Life, vol. 10, (2016), pp. 121-124.

[13] S. H. Kim, "An Analysis of Management Efficiency of Korean IT Service Firms", Master's Thesis, Information and Communications University, (2007).

\section{Author}

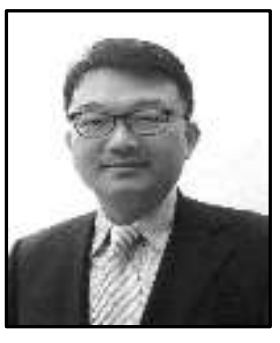

HyunWoo Goh, he received the B.S., M.S. and Ph.D. degrees from the Dept. of Industrial Engineering, Hanyang University, Seoul, Korea, in 1987, 1989 and 1995, respectively. He was a General Director of Korea Industrial Management System Society from 2002-2006. Currently, he is a Professor of Dept. of Industrial Management System Engineering, Seokyeong University, Seoul, Korea. His research areas include Data Envelopment Analysis (DEA), Supply Chain Management (SCM) and system dynamics. 
International Journal of Advanced Science and Technology

Vol.115 (2018) 